\title{
1 Towards a better understanding of the origins of microlens arrays in Mesozoic ophiuroids
}

\section{2 and asteroids}

4 Przemysław Gorzelak ${ }^{1 *}$, Imran A. Rahman ${ }^{2}$, Samuel Zamora ${ }^{3,4}$, Arkadiusz Gąsiński ${ }^{5}$, Jerzy

$5 \quad$ Trzciński ${ }^{6}$, Tomasz Brachaniec ${ }^{7}$, and Mariusz A. Salamon ${ }^{8 *}$

6

$7{ }^{1}$ Institute of Paleobiology, Polish Academy of Sciences, Twarda 51/55, 00-818 Warsaw, Poland,

$8 \quad$ email: pgorzelak@twarda.pan.pl

$9 \quad{ }^{2}$ Oxford University Museum of Natural History, Parks Road, Oxford, OX1 3PW, United

10 Kingdom

$11{ }^{3}$ Instituto Geológico y Minero de España (IGME), C/Manuel Lasala, 44, 9² B, 50006, Zaragoza,

12 Spain

$13{ }^{4}$ Unidad Asociada en Ciencias de la Tierra, Universidad de Zaragoza-IGME, Zaragoza, Spain

$14{ }^{5}$ Institute of Geochemistry, Mineralogy and Petrology, Faculty of Geology, University of

15 Warsaw, Żwirki i Wigury 93, 02-089 Warsaw, Poland

$16{ }^{6}$ Institute of Hydrogeology and Engineering Geology, Faculty of Geology, University of

17 Warsaw, Żwirki i Wigury 93, 02-089 Warsaw, Poland

$18{ }^{7}$ Department of Geochemistry, Mineralogy and Petrography, Faculty of Earth Sciences,

19 University of Silesia, Będzińska 60, 41-200 Sosnowiec, Poland

$20{ }^{8}$ Department of Palaeontology and Stratigraphy, Faculty of Earth Sciences, University of Silesia, 21 Będzińska 60, 41-200 Sosnowiec, Poland. 


\section{Abstract}

25 Echinoderms are characterized by a calcite endoskeleton with a unique microstructure, which is

26 optimized for multiple functions. For instance, some light-sensitive ophiuroids (Ophiuroidea)

27 and asteroids (Asteroidea) possess skeletal plates with multi-lens arrays that are thought to act as

28 photosensory organs. The origins of these lens-like microstructures have long been unclear. It

29 was recently proposed that the complex photosensory systems in certain modern ophiuroids and

30 asteroids could be traced back to at least the Late Cretaceous (ca. $79 \mathrm{Ma}$ ). Here, we document

31 similar structures in ophiuroids and asteroids from the Early Cretaceous of Poland (ca. 136 Ma)

32 that are approximately 57 million years older than the oldest asterozoans with lens-like

33 microstructures described thus far. We use scanning electron microscopy, synchrotron

34 tomography, and electron backscatter diffraction combined with focused ion beam microscopy to

35 describe the morphology and crystallography of these structures in exceptional detail. The results

36 indicate that, similar to Recent light-sensitive ophiuroids, putative microlenses in Cretaceous

37 ophiuroids and asteroids exhibit a shape and crystal orientation that would have minimized

38 spherical aberration and birefringence. We suggest that these lens-like microstructures evolved

39 by secondary deposition of calcite on pre-existing porous tubercles that were already present in 40 ancestral Jurassic forms.

42 Key words: echinoderms, photosensitivity, Cretaceous, microlenses, calcite, tomography

\section{Introduction}

45 Echinoderms exploit their calcite endoskeleton for a variety of functions, including support, 46 movement, protection, food gathering, and ion storage (Smith 1990). This multipurpose tissue 
47 can be modelled into different shapes through the use of an amorphous calcium carbonate

48 precursor and the involvement of organic molecules during the biomineralization process (e.g.

49 Politi et al. 2004; Killian and Wilt 2008). The role of the echinoderm skeleton in vision was

50 suggested long ago (Raup 1966), but it is only recently that scientists have begun to examine this

51 phenomenon more closely. For instance, it has been shown that some sea urchins use their

52 skeleton as a shielding device for photoreceptor cells, forming numerous compound eye units

53 (Ullrich-Lüter et al. 2011). Another, strikingly different example of using the skeleton as a part

54 of the photoreceptive system is reported for the light-sensitive ophiocomid ophiuroid Ophiocoma

55 wendtii (Hendler and Byrne 1987). This species changes colour from uniformly dark brown

56 during the day to grey and black banded at night when it is most active (Hendler 1984). This

57 change is not connected with camouflage, but is related to their sensitivity to light (Hendler

58 2004). Indeed, it has been shown that this species possesses calcitic microlens arrays, surrounded

59 by pigment-filled chromatophores, which are able to focus light onto presumably light-sensitive

60 nerve bundles (Aizenberg et al. 2001). These microlenses are micron-scale in size, lightweight,

61 mechanically strong, aberration-free, and birefringence-free, all properties that may be applicable

62 to materials science (Zhang 2003; Aizenberg and Hendler 2004). Such lens-like microstructures

63 are also present in other light-sensitive ophiocomid species, but do not occur in light-insensitive

64 species (Hendler and Byrne 1987). Interestingly, photosensitive proteins (both rhabdomeric and

65 ciliary opsins) have been recently identified in the arms of the ophiocomid Ophiopsila aranea,

66 which possesses similar lens-like microstructures (Delroisse et al. 2016). This species exhibits a

67 high sensitivity to green wavelengths of light, indicating a directional phototaxis likely enhanced

68 by the microlenses (Delroisse et al. 2016). 
Comparable, though not homologous, structures are also present in some shallow-water

70 asteroids (e.g. goniasterids and archasterids) that live within the photic zone (e.g. Mah 2005;

71 Vinogradova et al. 2016). Although focusing light through microlens arrays has yet to be

72 confirmed in these taxa, their morphology is strikingly similar to the microlenses of ophiocomid

73 ophiuroids, and they are thus considered to be involved in photoreception (e.g. Döderlein 1898;

74 Hendler and Byrne 1987; Dubois and Hayt 1990; Mah 2005; Vinogradova et al. 2016). Notably,

75 in the case of the asteroid Iconaster, it has recently been shown that the microlenses are largely

76 absent in deep-water sister and outgroup taxa, implying that their convergent expression is

77 related to the exposure to sunlight (Mah 2005). The origin of microlens arrays in asterozoans (the

78 clade comprising ophiuroids and asteroids) is unclear. Similar lens-like microstructures were

79 recently documented in some Late Cretaceous ophiuroids and asteroids from Poland, implying

80 that the origins of these putative complex photosensory systems should be traced back to at least

81 the Campanian (ca. $79 \mathrm{Ma}$ ) (Gorzelak et al. 2014). Although external faces in fossil asterozoans

82 are commonly covered by various types of granular ornamentation, sometimes referred to as

83 tubercles or pustules (e.g. Blake et al. 2000; Villier et al. 2004), in-depth microstructural

84 investigations and functional interpretations of these structures are largely lacking. In this paper,

85 we use state-of-the-art imaging techniques to describe the morphology of isolated plates from the

86 arms of select Mesozoic ophiuroids and asteroids, and compare these to modern specimens with

87 lens-like microstructures. The results shed light on the origins and development of microlens

88 arrays in asterozoans.

89

90 Materials and Methods 
91 Isolated asterozoan plates with lens-like microstructures were collected by one of us (MAS)

92 during the course of field work on Cretaceous crinoids (Salamon 2009). The material came from

93 late Valanginian (ca. $136 \mathrm{Ma}$ ) silts intercalated with clayey sands, which are exposed in an

94 abandoned brick-pit in Wąwał near Tomaszów Mazowiecki (central Poland, 51²9'50’'N

$9520^{\circ} 3^{\prime} 05^{\prime}$ 'E, see Kaim 2001). For comparative purposes, we also surveyed mostly isolated plates

96 (>2000 elements in total) of shallow-water ophiuroids and asteroids (mainly belonging to the

97 families Ophiuridae, Goniasteridae, Astropectinidae and Benthopectinidae) from the Triassic,

98 Jurassic and Cretaceous of Poland, Lithuania and Czech Rep., which are housed in the

99 collections of the Department of Earth Sciences, Laboratory of Palaeontology and

100 Biostratigraphy, University of Silesia (GIUS), Sosnowiec, Poland (Electronic Supplementary

101 Material; for detailed description of sampling sites see Salamon and Zatoń 2007; Salamon 2008;

102 Villier 2008; Zatoń et al. 2008; Gorzelak and Salamon 2009; Salamon and Gorzelak 2010; Hess

103 et al. 2011; Salamon et al. 2012).

104 Plates of a specimen of the Recent photosensitive ophiuroid $O$. wendtii from southeastern

105 Florida, which displays lens-like microstructures, were also investigated. Soft tissues in this

106 ophiuroid were removed by soaking the specimen in a 5\% sodium hypochlorite solution for

1072 hours at room temperature.

108 High-resolution observations on carbon-coated plates of Recent and fossil specimens

109 were performed with a Philips XL-20 Scanning Electron Microscope (SEM) at the Institute of

110 Paleobiology of the Polish Academy of Sciences in Warsaw (accelerating voltage $=25 \mathrm{kV}$,

111 working distance $=34 \mathrm{~mm}$ ). In addition, the three-dimensional microstructure of select plates

112 was studied using non-destructive propagation-based phase-contrast synchrotron radiation X-ray

113 tomographic microscopy. The small size of the samples and their low attenuation contrast 
114 necessitated high-resolution synchrotron-based phase-contrast imaging instead of conventional

115 lab-based X-ray micro-tomography (Sutton et al. 2014; Cunningham et al. 2014). Tomography

116 was performed at the TOMCAT beamline (Stampanoni et al. 2007) of the Swiss Light Source,

117 Paul Scherrer Institut, Villigen, Switzerland. The specimens was mounted on SEM stubs with

118 nail polish and scanned at $4 \times$ optical magnification using an X-ray energy of $20 \mathrm{keV}, 1501$

119 projections, and an exposure time of $125 \mathrm{~ms}$. The detector consisted of a $20-\mu \mathrm{m}$ thick LAG:Ce

120 scintillator and a CCD camera, and the distance between the sample and the detector

121 (propagation distance) was set at $40 \mathrm{~mm}$. Slices were reconstructed using in-house software,

122 including custom algorithms for ring artefact reduction and phase retrieval. This provided

123 tomographic datasets with a voxel size of $1.625 \mu \mathrm{m}$.

124 In order to non-destructively aquire precise crystallographic orientation data of lenses

125 from Recent and fossil specimens, we used a focused ion beam (FIB) microscope to carefully

126 remove only small portions of calcitic material (previously coated with a $20 \mathrm{~nm}$ layer of gold)

127 from the top of selected lenses. FIB-based milling was usually operated at $30 \mathrm{kV}$ and the

128 following successive beam currents were typically used: 4nA; 1nA; 600 pA; 240 pA; 120 pA.

129 Finally, low voltage $(5 \mathrm{kV}-240 \mathrm{pA})$ FIB milling was applied to remove the damaged surfaces.

130 After this procedure, electron backscatter diffraction (EBSD) data were collected from fresh

131 surfaces (up to about $20 \times 20 \mu \mathrm{m}$ ) without coating them, using an acceleration voltage of 15-25

$132 \mathrm{kV}$ and a beam current of about $15 \mathrm{nA}(120 \mu \mathrm{m}$ aperture and the "high current" mode). FIB-

133 EBSD data were acquired and processed using a Quantax CrystAlign 200 system equipped with

134 e-Flash detector installed on the Auriga 60 FIB-SEM microscope at the Faculty of Geology,

135 University of Warsaw. 


\section{Results}

138 Characteristic arrays of internally compact calcitic structures were identified on several isolated

139 plates of asterozoans collected from the Wąwał locality (two radial shields and one dorsal arm

140 plate of Stegophiura? and nine marginal plates of taxa belonging to the family Goniasteridae;

141 Figs. 1d-i, 2c-g). These consist of thick imperforate stereom with a spherical top and an

142 aspherical bottom. The fossil echinoderms have lens-like microstructures that are identical to one

143 another and are very similar to those present in Late Cretaceous and Recent echinoderms

144 (Gorzelak et al., 2014) (Figs. 1a-c, 2a, b). Indeed, the diameter of the structures ( 40-140 $\mu \mathrm{m})$

145 falls within the range of microlenses of living echinoderms $(\sim 30-150 \mu \mathrm{m})$ (Dubois and Hayt

146 1990). Detailed observations of these fossil plates using propagation-based phase-contrast

147 synchrotron radiation X-ray tomographic microscopy confirmed that, similar to Recent light-

148 sensitive echinoderms, internal labyrinthic stereom with trabeculae that are about $15 \mu \mathrm{m}$ thick

149 and irregular pores extends dorsally into a regular array of lens-like microstructures with a

150 Huygensian shape, possibly involved in minimizing spherical aberration (Fig. 2c-e).

151 Furthermore, the high-resolution electron backscatter diffraction data indicate that the orientation

152 of the calcite crystallographic c-axis in these Early Cretaceous forms (Fig. 3a-d) lies parallel to

153 the lens axis and slightly fans out at lens edges, a pattern that is also present in Recent

154 photosensitive ophiuroids (Fig. 3e-h). This pattern was also recognized in the schizochroal

155 lenses of trilobites and is even seen in trilobite lenses that underwent coarse recrystallization

156 (Torney et al. 2014). This specific crystallographic orientation eliminates birefringence of calcite

157 (division of light into two components).

158 Microstructural inspection of asterozoans from other localities shows that granular

159 ornamentation on plate surfaces is not rare among older (pre-Cretaceous) ophiuroids and 
160 asteroids. However, tubercle ornamentation patterns in Triassic-Jurassic forms are clearly

161 different from the microlenses of Recent and Cretaceous echinoderms. First, these tubercles

162 commonly coalesce locally to form irregular ridges and are rarely arranged in an apparently

163 regular pattern (e.g. Villier et al. 2004; Villier 2008, Gale 2011). Furthermore, although some

164 seem to be comprised of thin imperforate stereom, internally they are typically porous and do not

165 exhibit a characteristic lens-like structure (Figs. $1 \mathrm{j}-1,2 \mathrm{~h}-\mathrm{j}$ ). Finally, in contrast to the microlenses

166 of Recent shallow-water asterozoans, which are mainly located on the dorsal plate surface,

167 tubercles in pre-Cretaceous forms can also occur on the ventral side (Blake et al. 2000) and may

168 be present in deep-water taxa (Villier et al. 2009). As stressed above, the function of this

169 granular ornamentation is not well understood; some tubercles supported moveable spines (e.g.

170 Villier et al. 2004; Blake et al. 2000), but the function of the others is unknown.

171

\section{Discussion}

173 Echinoderms exhibit a wide range of photoreceptive abilities (e.g. Yoshida 1966; Yamamoto

174 and Yoshida 1978; Garm and Nilsson 2014). However, in contrast to the calcitic and non-

175 biomineralized lenses that widely occur across arthropods (e.g. Zhao et al. 2013; Torney et al.

176 2014), most echinoderm species appear to lack discrete organs for light perception.

177 Photosensitivity in these echinoderms is chiefly thought to be related to diffuse dermal and/or

178 neural light receptors, although these may be localized in specialized body parts (Delroisse et al.

179 2016). A key exception is the case of the calcitic microlenses possessed by some shallow-water

180 ophiuroids (e.g. ophiocomids) and asteroids (e.g. goniasterids). Until now, however, little was

181 known about the origins of these lens-like microstructures. 
In Recent echinoderms, the external imperforate stereom layer, which is used to construct

183 the microlenses, is formed via two phases of biomineralization, i.e. deposition of porous stereom

184 that is secondarily filled by calcite (Heatfield 1971; Dubois and Hayt 1990). Our close

185 examination of some dorsal arm plates of the Recent ophiuroid $O$. wendtii reveals that some

186 microlenses are incompletely formed and are still locally porous, confirming the two-step model

187 of their formation (Dubois and Hayt 1990) (Figs. 1a, 2a). Interestingly, tubercle ornamentation in

188 pre-Cretaceous asterozoans examined in this study is typically internally porous, whereas it is

189 compact and imperforate in some younger, Cretaceous forms. Based on these morphological,

190 developmental, and paleontological data, we suggest that lens-like microstructures in Cretaceous

191 asterozoans likely evolved by secondary deposition of calcite on the pre-existing internally

192 porous tubercles that were already present in ancestral Jurassic forms.

193 It has been hypothesized that visual systems with microlenses were independently

194 acquired in ophiuroids and asteroids by the Late Cretaceous (Gorzelak et al. 2014), and this

195 could be linked to the onset of increased predation pressure during the Mesozoic Marine

196 Revolution (MMR), which resulted in the evolution of many antipredatory traits in benthic

197 organisms, including echinoderms (Vermeij 1977; Gorzelak et al. 2012; 2014). This predation

198 hypothesis is consistent with behavioural observations of the Recent ophiuroid $O$. wendtii, which

199 is able to escape from their predators, such as Perciformes fish, presumably thanks in part to its

200 complex visual system (Hendler 1984). Notably, recent molecular clock analyses suggest a Late

201 Jurassic origin of the common ancestral lineage of Perciformes fish, with a subsequent familial

202 radiation during the Cretaceous (Wei et al. 2014). Moreover, independent data on the frequencies

203 of sublethal arm damage (regenerating arms) in fossil ophiuroids and the temporal distributional 
204 patterns of dense ophiuroid populations both support the hypothesis that predation pressure on 205 ophiuroids increased in the Cretaceous (Aronson 1987, 1989, 1991).

Although a defensive function of the visual system with microlenses has yet to be tested

207 in asteroids, it is likely that these structures might have provided an advantage not only for

208 finding food, but also for avoiding predators, including Perciformes fish, which are likewise

209 known to feed on asteroids (Walker 1978; Sweatman 1994).

210 Our new data push back the origins of this putative visual system considerably, into the

211 Early Cretaceous. This timing is roughly coincident with the MMR, which is thought to have

212 started during the Jurassic and continued at an accelerated pace during the Cretaceous (Vermeij

213 1977). The simultaneous appearance of apparently similar lens-like microstructures in two

214 distantly-related echinoderm groups, which ancestrally lacked such traits, is a clear case of

215 convergence. We hypothesize that some ophiuroid and asteroid lineages, occupying the same

216 ecological niches and facing similar selective pressures, might have independently evolved

217 similar photosensitive organs to reduce the risk of predation.

\section{Acknowledgments}

220 This work was completed while the first author was a recipient of a grant from the Polish

221 National Science Centre (NCN) Grant number DEC-2011/03/N/ST10/04798 and was performed

222 in part in the NanoFun laboratory co-financed by the European Regional Development Fund

223 within the Innovation Economy Operational Programme POIG.02.02.00-00-025/09. IAR was

224 funded by an 1851 Royal Commission Research Fellowship. SZ was funded by grants RYC-

225 2012-10576 and CGL2013-48877 from the Spanish MINECO. We acknowledge the Paul

226 Scherrer Institut, Villigen, Switzerland for the provision of synchrotron radiation beamtime on 
227 the TOMCAT beamline at the Swiss Light Source and thank Professor Charles G Messing (Nova

228 Southeastern University) for providing the extant ophiuroid specimen. We also thank two

229 anonymous reviewers for their supportive comments.

230

$231 \quad$ Ethical standards

232 Investigations comply with the current laws of the country in which they were performed.

233

234 Conflict of interests

235 The authors declare that they have no conflict of interest.

236

237 References

238

239 Aizenberg, J., \& Hendler, G. (2004). Designing efficient microlens arrays: lessons from nature.

$240 \quad$ Journal of Materials Chemistry, 14, 2066-2072.

241 Aizenberg, J., Tkachenko, A., Weiner, S., Addadi, L., \& Hendler, G. (2001). Calcitic

242 microlenses as part of the photoreceptor system in brittlestars. Nature, 412, 819-822.

243 Aronson, R.B. (1987). Predation on fossil and Recent ophiuroids. Paleobiology, 13, 187-192.

244 Aronson, R.B (1989). A community-level test of the Mesozoic marine revolution theory.

$245 \quad$ Paleobiology, 15, 20-25.

246 Aronson, R.B. (1991). Predation, physical disturbance and sub-lethal arm damage in ophiuroids:

247 a Jurassic-Recent comparison. Marine Ecology Progress Series, 74, 91-97. 
Blake, D.B., Tintori, A., \& Hagdorn, H. (2000). A new asteroid (Echinodermata) from the Norian (Triassic) Calcare di Zorzino of northern Italy: its stratigraphic occurrence and

Cunningham, J.A., Rahman, I.A., Lautenschlager, S., Rayfield, E.J., \& Donoghue, P.C.J. (2014). phylogenetic significance. Rivista Italiana di Paleontologia e Stratigrafia, 106, 141-156. A virtual world of palaeontology. Trends in Ecology \& Evolution, 29, 347-357.

Delroisse., J., Mallefet, J. \& Flammang, P. (2016). De Novo Adult Transcriptomes of Two European Brittle Stars: Spotlight on Opsin-Based Photoreception. PLoS ONE, 11:e0152988. doi:10.1371/journal.pone.0152988

Döderlein, L. (1898). Ueber "Krystallkörper" bei Seesternen. Denkschriften der Medizinisch Naturwissenschaftlichen Gesellschaft zu Jena, 8, 491-494.

Dubois, P., \& Hayt, S. (1990). Ultrastructure des ossicules d'échinodermes à stéréome non perforé. In C., De Ridder, P., Dubois, M.C., Lahaye, \& M., Jangoux (Eds.), Echinoderm Research: (pp. 217-223). Rotterdam, Balkema.

Gale, A. (2011). Asteroidea (Echinodermata) from the Oxfordian (Late Jurassic) of Savigna, Départment [sic!] du Jura, France. Swiss Journal of Palaeontology, 130, 69-89.

Garm, A., \& Nilsson, D.E. (2014). Visual navigation in starfish: first evidence for the use of vision and eyes in starfish. Proceedings of the Royal Society B: Biological Sciences, 281, 2013-3011.

Gorzelak, P., \& Salamon, M.A. (2009). Signs of benthic predation on Late Jurassic stalked crinoids, preliminary data. Palaios, 24, 70-73.

Gorzelak, P., Salamon. M.A., \& Baumiller, T.K. (2012). Predator-induced macroevolutionary trends in Mesozoic crinoids. Proceedings of the National Academy of Sciences of the United States of America, 109, 7004-7007. 
271 Gorzelak, P., Salamon, M.A., Lach, R., Loba, M., \& Ferré, B. (2014). Microlens arrays in the 272 complex visual system of Cretaceous echinoderms. Nature Communications, 5:3576, doi: 10.1038/ncomms4576.

274 Heatfield, B.M. (1971). Growth of the calcareous skeleton during regeneration of spines of the 275 sea urchin Strongylocentrotus purpuratus (Stimpson); a light and scanning electron microscope study. Journal of Morphology, 134, 57-90.

277 Hendler, G. (1984). Brittlestar color-change and phototaxis (Echinodermata: Ophiuroidea: 278 Ophiocomidae). Marine Ecology, 5, 379-401.

279 Hendler, G., \& Byrne, M. (1987). Fine structure of the dorsal arm plate of Ophiocoma wendti (Echinodermata, Ophiuroidea). Zoomorphology, 107, 261-272.

281 Hendler, G. (2004). An echinoderm's eye view of photoreception and vision. In T. Heinzeller, \& 282 J. Nebelsick (Eds.), Echinoderms; Munchen; Proceedings of the 11th International Echinoderm Conference. (pp. 339-350). Leiden: A.A. Balkema Publishers.

Hess, H., Salamon, M.A., \& Gorzelak, P. (2011). Late Jurassic-Early Cretaceous (TithonianBerriasian) cyrtocrinids from south-eastern Poland. Neues Jahrbuch für Geologie und Paläontologie, Abhandlungen, 260, 119-128.

Kaim, A. (2001). Faunal dynamics of juvenile gastropods and associated organisms across the Valanginian transgression-regression cycle in central Poland. Cretaceous Research, 22, 333-351.

Killian, C.E., \& Wilt, F.H. (2008). Molecular aspects of biomineralization of the echinoderm endoskeleton. Chemical Reviews, 108, 4463-4474.

292 Mah, C.L. (2005). A phylogeny of Iconaster and Glyphodiscus (Goniasteridae; Valvatida; 293 Asteroidea) with descriptions of four new species. Zoosystema, 27, 131-167. 
294 Politi, Y., Arad, T., Klein, E., Weiner, S., \& Addadi, L. (2004). Sea urchin spine calcite forms 295 via a transient amorphous calcium phase. Science, 306, 1161-1164.

296 Raup, D.M. (1966). The endoskeleton. In R.A. Boolootian (Ed.), Physiology of Echinodermata 297 (pp. 379-395). New York: Interscience.

298 Salamon, M.A. (2008). The Callovian (Middle Jurassic) crinoids from northern Lithuania.

299 Paläontologische Zeitschrift, 82, 269-278.

300 Salamon, M.A. (2009). Early Cretaceous (Valanginian) sea lilies (Echinodermata, Crinoidea) 301 from Poland. Swiss Journal of Geosciences, 102, 77-88.

302 Salamon, M.A., \& Zatoń, M. (2007). Late Bajocian through Callovian (Middle Jurassic) crinoid fauna from the epicontinental deposits of Poland. Swiss Journal of Geosciences, 100, 153164.

Salamon, M.A., \& Gorzelak, P. (2010). Cyrtocrinids (Echinodermata, Crinoidea) from Upper Jurassic Štramberk-type limestones in southern Poland. Palaeontology, 53, 869-885.

Salamon, M.A., Niedźwiedzki, R., Lach, R., Brachaniec, T., \& Gorzelak, P. (2012). Ophiuroids

Smith, A.B. (1990). Biomineralization in echinoderms. In J.G. Carter (Ed.), Skeletal biomineralization: patterns, processes, and evolutionary trends (pp. 413-443). New York:

313 Stampanoni, M., et al. (2007). TOMCAT: a beamline for tomographic microscopy and coherent radiology experiments. AIP Conference Proceedings, 879, 848.

315 Sutton, M.D., Rahman, I.A., \& Garwood, R.J. (2014). Techniques for Virtual Palaeontology. Wiley. 
317 Sweatman, H.P.A. (1995). A field study of fish predation on juvenile crown-of-thorns starfish.

$318 \quad$ Coral reefs, $14(1), 47-53$.

319 Torney, C., Lee, M.R., \& Owen, A.W. (2014). Microstructure and growth of the lenses of 320 schizochroal trilobite eyes. Palaeontology, 57, 783-799.

321 Ullrich-Lüter, E.M, Dupont, S., Arboleda, E., Hausen, H., \& Arnone, M.I. (2011). Unique system of photoreceptors in sea urchin tube feet. Proceedings of the National Academy of Sciences of the United States of America, 108, 8367-8372.

324 Vermeij, G.J. (1977). The Mesozoic marine revolution; evidence from snails, predators and 325 grazers. Paleobiology, 3, 245-258.

326 Villier, L. (2008). Sea star ossicles from the Callovian black clays of the Łuków area, eastern 327 Poland. Neues Jahrbuch für Geologie und Paläontologie, Abh., 247, 147-160.

328 Villier, L., Charbonnier, S., \& Riou, B. (2009). Sea stars from Middle Jurassic Lagerstätte of La Volute sur Rhône (Ardèche, France). Journal of Paleontology, 83, 389-398.

330 Villier, L., Kutscher, M., \& Mah, C.H.L. (2004). Systematics and palaecology of middle Toarcian Asteroidea (Echinodermata) from the 'Seuil du Poitou', Western France.

333 Vinogradova, E., Ruíz-Zepeda, F., Plascencia-Villa, G., \& José-Yacamán, M. (2016). Calcitic microlens arrays in Archaster typicus: microstructural evidence for an advanced photoreception system in modern starfish. Zoomorphology, 135, 83-87.

336 Walker, M.H. (1978). Food and feeding habits of Lethrinus chrysostomus Richardson (Pisces: 337 Perciformes) and other Lethrinids on the Great Barrier Reef. Australian Journal of Marine 338 \& Freshwater Research 29(5):623-30. 
Wei, T., Sun, Y., Zhang, B., Wang, R., \& Xu, T. (2014). A Mitogenomic Perspective on the Phylogenetic Position of the Hapalogenys Genus (Acanthopterygii: Perciformes) and the Evolutionary Origin of Perciformes. PLoS ONE, 9(7), e103011.

Yamamoto, M., \& Yoshida, M. (1978). Fine structure of the ocelli of a synaptid holothurian, Opheodesoma spectabilis, and the effects of light and darkness. Zoomorphologie, 90, 1-17.

Yoshida, M. (1966). Photosensitivity. In R.A. Boolootian (Ed.), Physiology of Echinodermata

Zaton, M., Salamon, M.A., Boczarowski, A., \& Sitek, S. (2008). Taphonomy of dense ophiuroid

Zhang, S. (2003). Fabrication of novel biomaterials through molecular self-assembly. Nature accumulations from the Middle Triassic of Poland. Lethaia, 41(1), 47-58. Biotechnology, 21, 1171-1178.

Zhao, F., Bottjer, D.J., Hu, S., Yin, Z., \& Zhu, M. (2013). Complexity and diversity of eyes in Early Cambrian ecosystems. Scientific Reports, 3, 2751, doi:10.1038/srep02751

\section{FIGURE CAPTIONS}

357 Fig. 1. Skeletal microstructure of extant and fossil asterozoans. The images are scanning electron 358 micrographs (SEM). (a-c) Microlenses on a dorsal arm plate (DAP) of the Recent ophiuroid 359 Ophiocoma wendtii (ZPALV.42REC_op1); arrows in (a) show incompletely formed microlenses. (b) Magnification of a single lens. (c) Cross-section of a fractured single lens. (d-f)

361 Microlenses on a radial shield of the Early Cretaceous (Valanginian) ophiuroid Stegophiura? 
362 (GIUS 9-346801). (e) Magnification of a single lens. (f) Cross-section of a fractured single lens. 363 (g-i) Microlenses on a marginal plate of an Early Cretaceous (Valanginian) asteroid belonging to

364 the family Goniasteridae (GIUS 9-3468a1). (h) Magnification of a single lens. (i) Cross-section 365 of a fractured single lens. ( $\mathbf{j}-\mathbf{l})$ Granular ornamentation on a marginal plate of a Late Jurassic 366 asteroid belonging to the family Goniasteridae (GIUS 8-3577a1). (k) Magnification of a single 367 tubercle. (I) Cross-section of a fractured single tubercle. Dotted lines indicate lens morphology. 368

369 Fig. 2. Synchrotron slices illustrating internal microstructure of extant and fossil echinoderms.

370 (a, b) Contact (delineated by dotted line in (b)) between microlenses (L) comprised of compact

371 imperforate stereom layer and the underlying porous labyrinthic stereom (S) in a dorsal arm plate 372 (DAP) of the Recent ophiuroid Ophiocoma wendtii (ZPALV.42REC_op1); slices aligned 373 perpendicularly (a) or longitudinally (b) to the ossicle surface, arrows show incompletely formed 374 microlenses. (c-e) Contact (delineated by dotted lines) between microlenses (L) forming a 375 compact imperforate stereom layer and the underlying porous labyrinthic stereom (S) in a 376 marginal plate of an Early Cretaceous (Valanginian) asteroid belonging to the family 377 Goniasteridae (GIUS 9-3468a1); slices aligned perpendicularly to the ossicle surface. (f, $\mathbf{g}$ ) 378 Examples (arrows) of characteristic "spoke-like" appearance of lens-like microstructure in a 379 marginal plate of an Early Cretaceous (Valanginian) asteroid belonging to the family 380 Goniasteridae (GIUS 9-3468a1) (f) and the ophiuroid Stegophiura? (GIUS 9-3468o1) (g) slices 381 aligned longitudinally to the ossicle surface close to the dorsal side. (h-j) Coarse rectilinear or 382 labyrinthic stereom (S) homogenously distributed within the marginal plates with granular 383 ornamentation of a Late Jurassic asteroid belonging to the family Goniasteridae (GIUS 8384 3577a1); slices aligned perpendicularly (h) or longitudinally $(\mathbf{i}, \mathbf{j})$ to the ossicle surface. 
386 Fig. 3. Crystallographic data obtained from fossil and Recent echinoderms. (a) SEM micrograph

387 of the lens of the Valanginian ophiuroid Stegophiura? (GIUS 9-3468o1) after FIB treatment

388 showing lens and calcite c-axis (red dotted line); dotted black rectangle indicates region

389 sectioned almost perpendicular to the lens axis from which EBSD data were collected (b-d). (b)

390 Pole figure with the orientation of the calcite c-axis in (d). (c) Graph showing misorientation

391 across the white line shown in (d), implying the presence of subdomains. (d) Combined

392 diffraction intensity and crystallographic orientation data with key to colour coding; the uniform

393 colour of calcite implies a uniform crystallographic orientation, dark areas in the interior indicate

394 poor diffraction due to the irregular topography after FIB treatment. (e) SEM micrograph of the

395 lens of the Recent ophiuroid Ophiocoma wendtii (ZPALV.42REC_op1) after FIB treatment

396 showing lens and calcite c-axis (red dotted line); dotted black rectangle indicates region

397 sectioned almost perpendicular to the lens axis from which EBSD data were collected (f-h). (f)

398 Pole figure showing the orientation of the calcite c-axis in (h). (g) Graph showing misorientation

399 across the white line shown in (h), implying the presence of subdomains. (h) Combined

400 diffraction intensity and crystallographic orientation data with key to colour coding; the uniform

401 colour of calcite implies a uniform crystallographic orientation, dark areas in the interior indicate

402 poor diffraction due to irregular topography after FIB treatment and/or presence of organic

403 inclusions. 

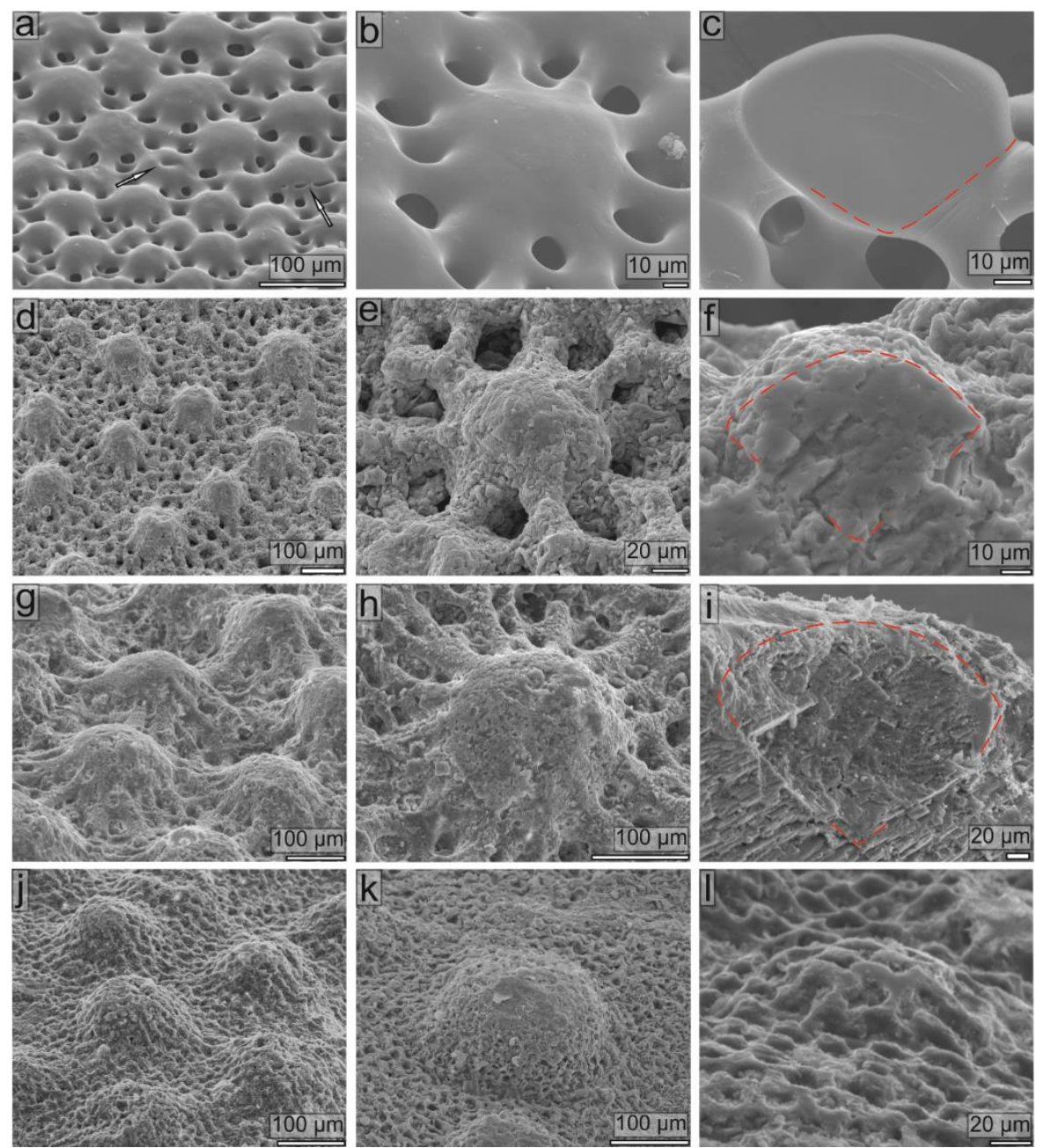

405

406 Fig. 1.

407 


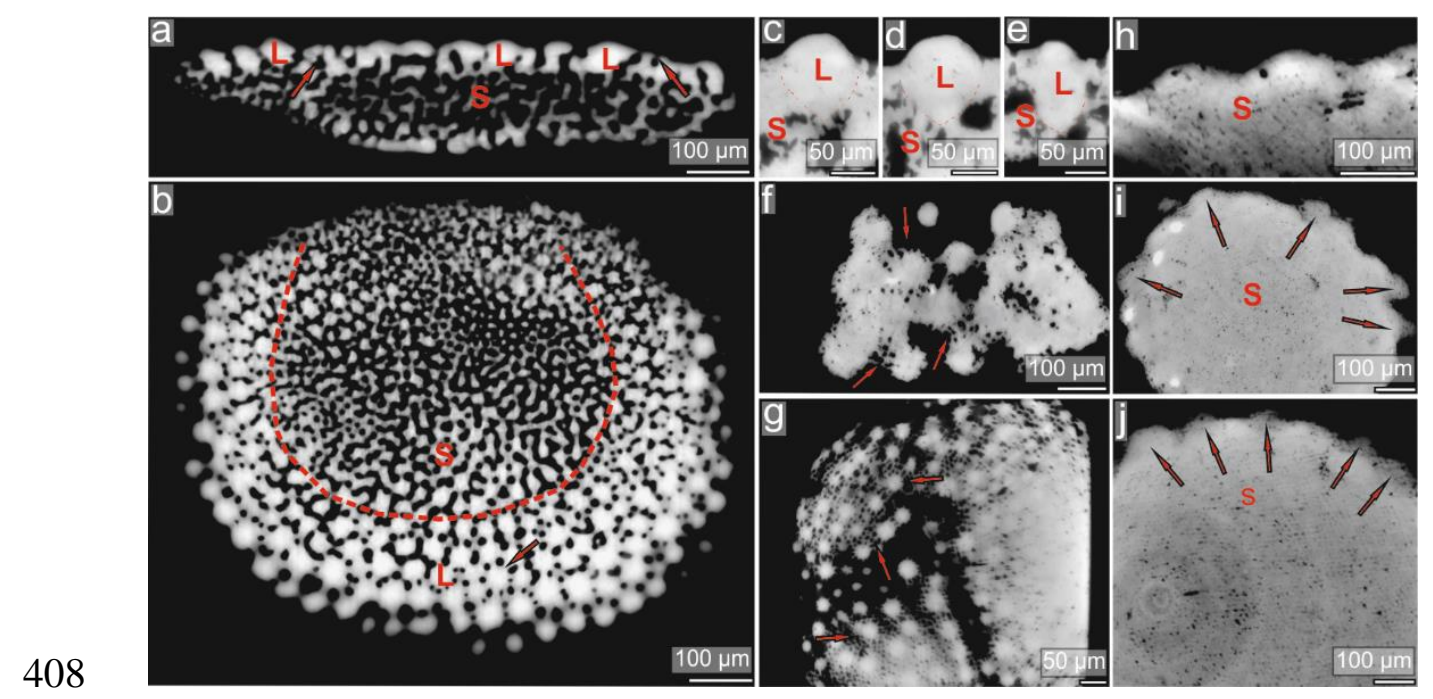

409 Fig. 2.

410 

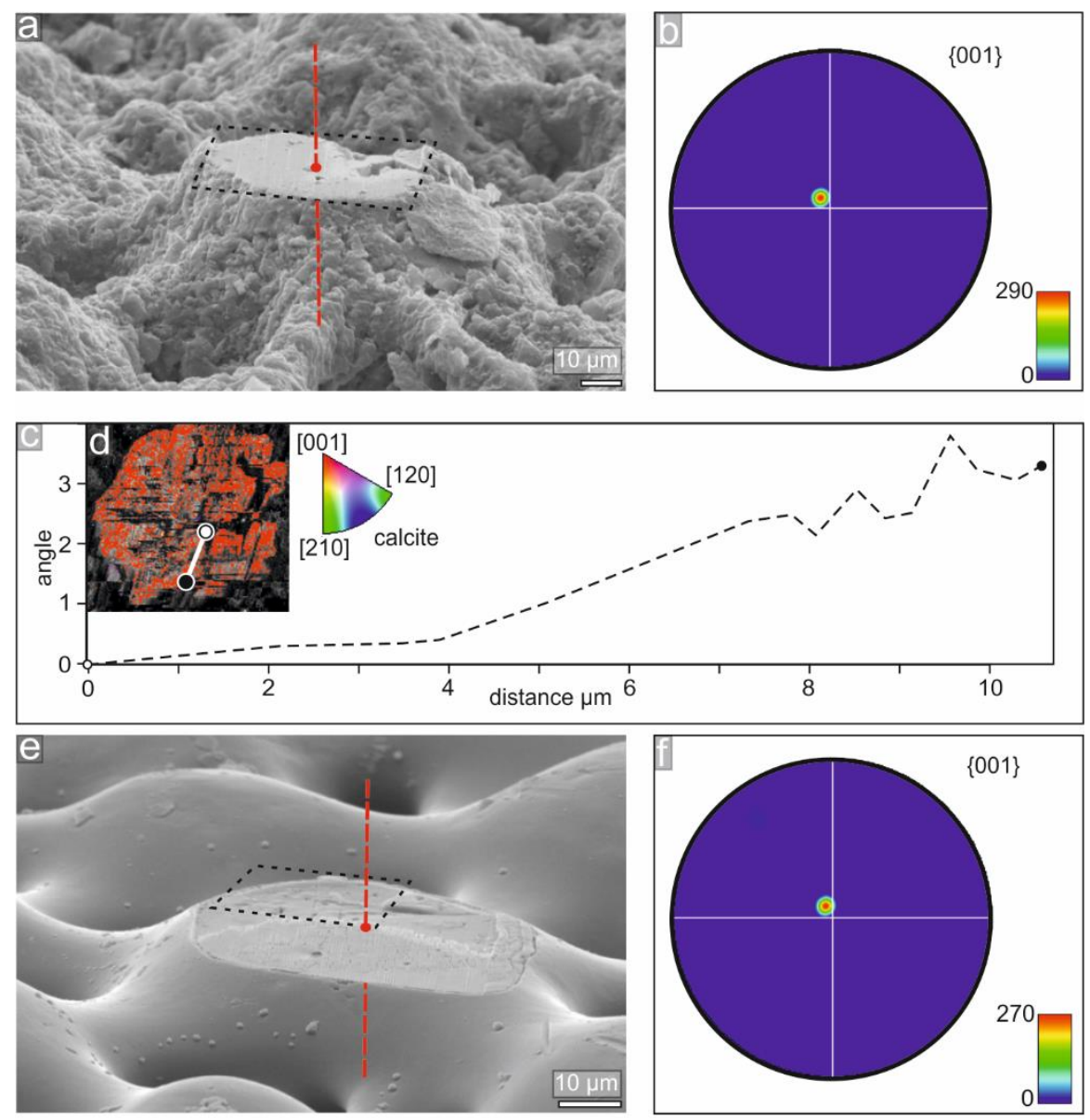

411

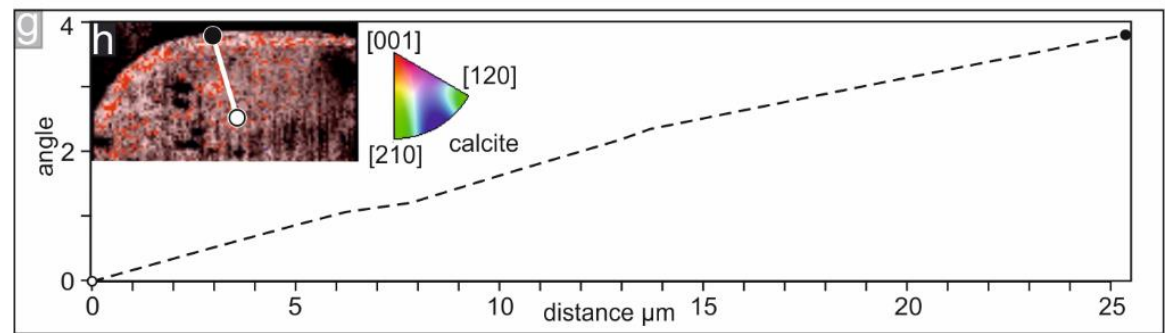

\section{Fig. 3.}

